\title{
Chromium-Based Alloys Strengthened by Ordered Phase Precipitation for Gas Turbine Applications
}

\author{
Didier LOCQ ${ }^{a}$, Pierre CARON ${ }^{b}$, Catherine RAMUSAT ${ }^{c}$ and Rémy MÉVREL ${ }^{d}$ \\ Office National d'Études et de Recherches Aérospatiales (ONERA) \\ BP 72 - 29 avenue de la division Leclerc - 92322 CHATILLON CEDEX - France \\ alocq@onera.fr, ${ }^{\mathrm{b}}$ caron@onera.fr, ${ }^{\mathrm{r}}$ ramusat@onera.fr, ${ }^{\mathrm{d}} \mathrm{mevrel@onera.fr}$
}

Key words: chromium-based alloy, microstructure, oxidation, creep.

\begin{abstract}
Chromium-based alloys are considered as potential candidates for applications in hot sections of aero engine turbines due to their high melting point and their moderate density. Some ternary $(\mathrm{Cr}-\mathrm{Ni}-\mathrm{Al})$ and quaternary $(\mathrm{Cr}-\mathrm{Ni}-\mathrm{Al}-\mathrm{Ti})$ alloys have been designed with the aim to induce precipitation of ordered strengthening precipitates and to promote the formation of a protective alumina scale. These alloys were cast using various techniques in order to assess their microstructural and mechanical properties and their oxidation resistance.
\end{abstract}

\section{Introduction}

Chromium-based alloys have been considered as potential candidates for high-temperature applications since the late 1940s because of their high melting point, high elastic modulus, low density and good oxidation resistance [1-3]. Research projects highlighted that the use of chromium or chromium-based alloys could present some drawbacks, with a high ductile-brittle transition temperature and a high nitrogen solubility which can cause severe embrittlement after exposure at high temperature in air. Moreover, it is to note that till today, it has not been proved that very good high-temperature mechanical properties could be reached.

The main goal of the present study is to design chromium-based alloys having both improved high-temperature mechanical and environmental resistance. The foreseen applications are static or rotating components of the high-temperature parts of an aero engine.

\section{Alloy design}

The objective was to design new chromium-based alloys strengthened by a coherent or semicoherent phase precipitation and protected from the aggressive environment by an alumina scale. Aluminium was selected as a major alloying element because it is likely to promote formation of an external alumina scale while, associated with nickel, it can participate to the precipitation of the intermetallic compounds $\beta-\mathrm{NiAl}$ and $\beta^{\prime}-\mathrm{Ni}_{2} \mathrm{AlTi}$ whose the crystalline structures and lattice parameters are compatible with those of chromium. Compared with the A2 structure of $\alpha-\mathrm{Cr}$ with a lattice parameter of $0.28839 \mathrm{~nm}$, the $\mathrm{NiAl}$ and $\mathrm{Ni}_{2} \mathrm{AlTi}$ phases have respectively an ordered $\mathrm{B} 2$ structure with a lattice parameter of $0.2888 \mathrm{~nm}$ [4] and a cubic L2 ${ }_{1}$ structure (also known as Heusler phase) with a lattice parameter equal to $0.5850 \mathrm{~nm}$ [5]. The five alloys of this study were thus selected in the ternary $\mathrm{Cr}-\mathrm{Ni}-\mathrm{Al}$ and the quaternary $\mathrm{Cr}-\mathrm{Ni}-\mathrm{Al}-\mathrm{Ti}$ systems. The nominal compositions of these alloys are listed in Table 1.

Table 1: Nominal chemical compositions of the chromium-based alloys [at. \%]

\begin{tabular}{|c|c|c|c|c|c|}
\hline Alloy System & Alloy & $\mathrm{Cr}$ & $\mathrm{Ni}$ & $\mathrm{Al}$ & $\mathrm{Ti}$ \\
\hline \multirow{2}{*}{ Ternary } & RT1 & 80 & 10 & 10 & - \\
\cline { 2 - 6 } & RT2 & 70 & 15 & 15 & - \\
\hline \multirow{3}{*}{ Quaternary } & RT7 & 80 & 10 & 6 & 4 \\
\cline { 2 - 6 } & RT6 & 70 & 15 & 9 & 6 \\
\cline { 2 - 6 } & RT4 & 60 & 20 & 12 & 8 \\
\hline
\end{tabular}




\section{Results}

Material processing. Alloys were prepared as small ingots $\left(30\right.$ to $\left.50 \mathrm{~cm}^{3}\right)$ either by arc melting in water-cooled copper crucible or by cold crucible levitation induction melting of high-purity materials under argon atmosphere. Some alloys were also prepared by vacuum induction melting in a ceramic mould under argon atmosphere and die-cast into a steel mould to obtain rods with a diameter of $15 \mathrm{~mm}\left(30 \mathrm{~cm}^{3}\right)$.

Some chromium-based alloy densities were measured by helium pycnometry and compared with those of typical blade nickel-based superalloys (Table 2). In an iso-volume context, these chromium alloys offer a 10-15\% mass reduction as compared with IN100 (one of the lightest blade superalloy) or about $25 \%$ mass reduction as compared with third- or fourth-generation single-crystal superalloy (with a typical density of 9 g.cm ${ }^{-3}$ ).

Table 2: Densities of chromium-based alloys and typical blade nickel-based superalloys

\begin{tabular}{|c|c|c|c|c|c|c|}
\hline Alloy & RT1 & RT2 & RT4 & RT7 & IN100 & René N6 \\
\hline Density $\left[\mathrm{g} . \mathrm{cm}^{-3}\right]$ & 6.90 & 6.80 & 6.74 & 6.87 & 7.75 & 8.97 \\
\hline
\end{tabular}

\section{Microstructures}

Cr-Ni-Al alloys. The microstructure of the as-cast ternary chromium-based alloys is mainly made up of $\alpha$-Cr dendrites ( $\alpha$ fraction increases as $\mathrm{Cr}$ content increases) embedded in $\beta$-NiAl or in the $\alpha+\beta$ eutectic (Fig. 1).

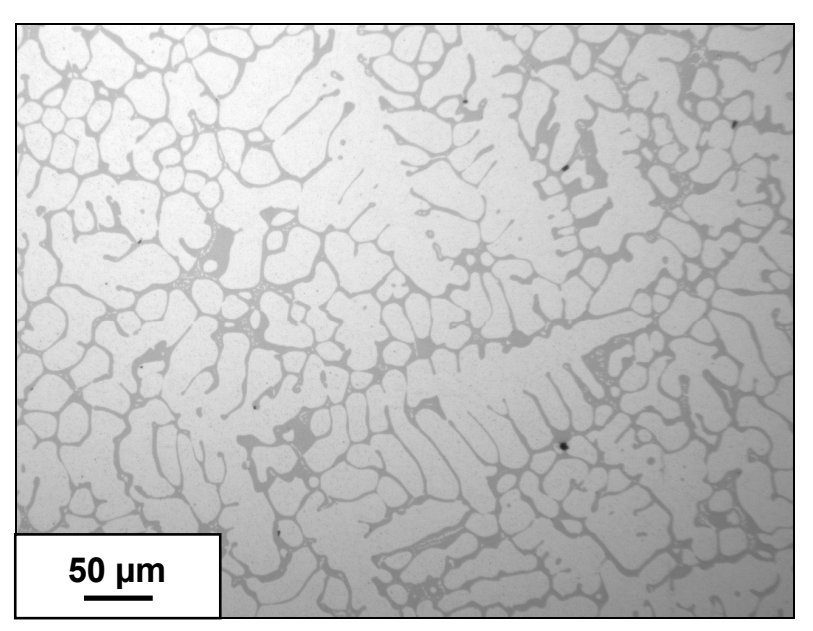

Fig. 1: RT2 alloy microstructure (optical microscopy).

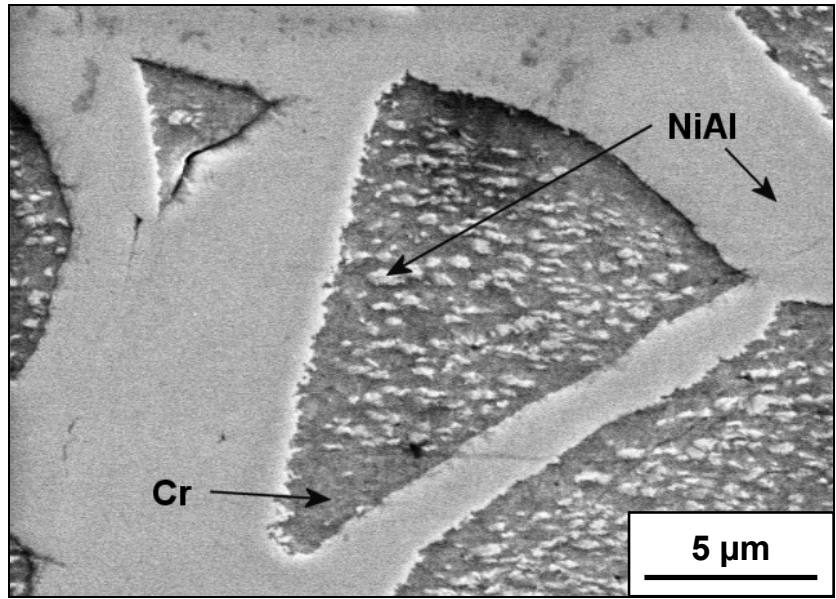

Fig. 2: NiAl precipitates in the $\alpha-\mathrm{Cr}$ phase of RT2 alloy (SEM).

The chemistry of each phase was analysed by semi-quantitative Energy Dispersive Spectrometry (EDS) in a scanning electron microscope (SEM). SEM observations showed that fine $\beta$-NiAl particles precipitated in the $\alpha$-Cr phase (Fig. 2).

Cr-Ni-Al-Ti alloys. Similarly to the ternary alloys, the microstructure of the quaternary alloys is mainly made up of $\alpha-\mathrm{Cr}$ dendrites here embedded in $\beta^{\prime}-\mathrm{Ni}_{2} \mathrm{AlTi}$ or in the $\alpha+\beta^{\prime}$ eutectic (Fig. 3). SEM and Transmission Electron Microscopy (TEM) observations showed that a very fine precipitation (mean diameter of $50 \mathrm{~nm}$ ) had taken place in the $\alpha$-Cr dendrites. X-ray diffraction analyses and electron diffraction patterns allowed identifying both $\alpha-\mathrm{Cr}$ and $\beta^{\prime}-\mathrm{Ni}_{2} \mathrm{AlTi}$ phases. 


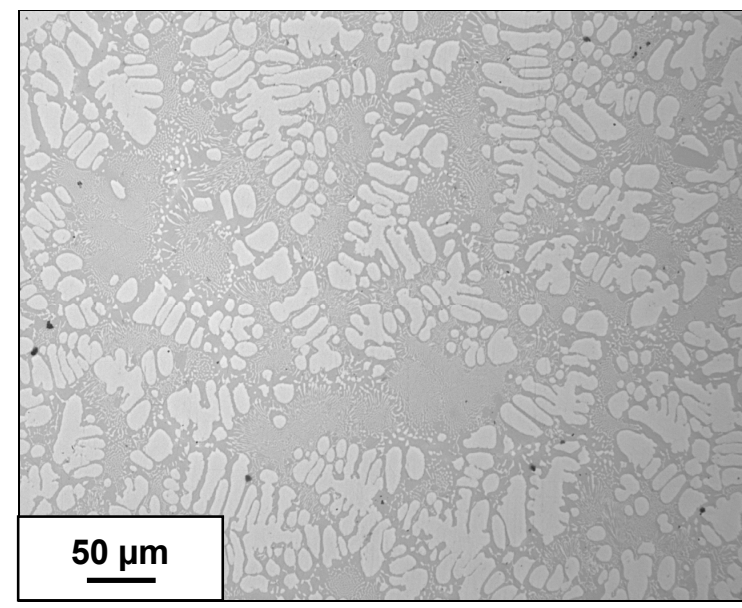

(a)
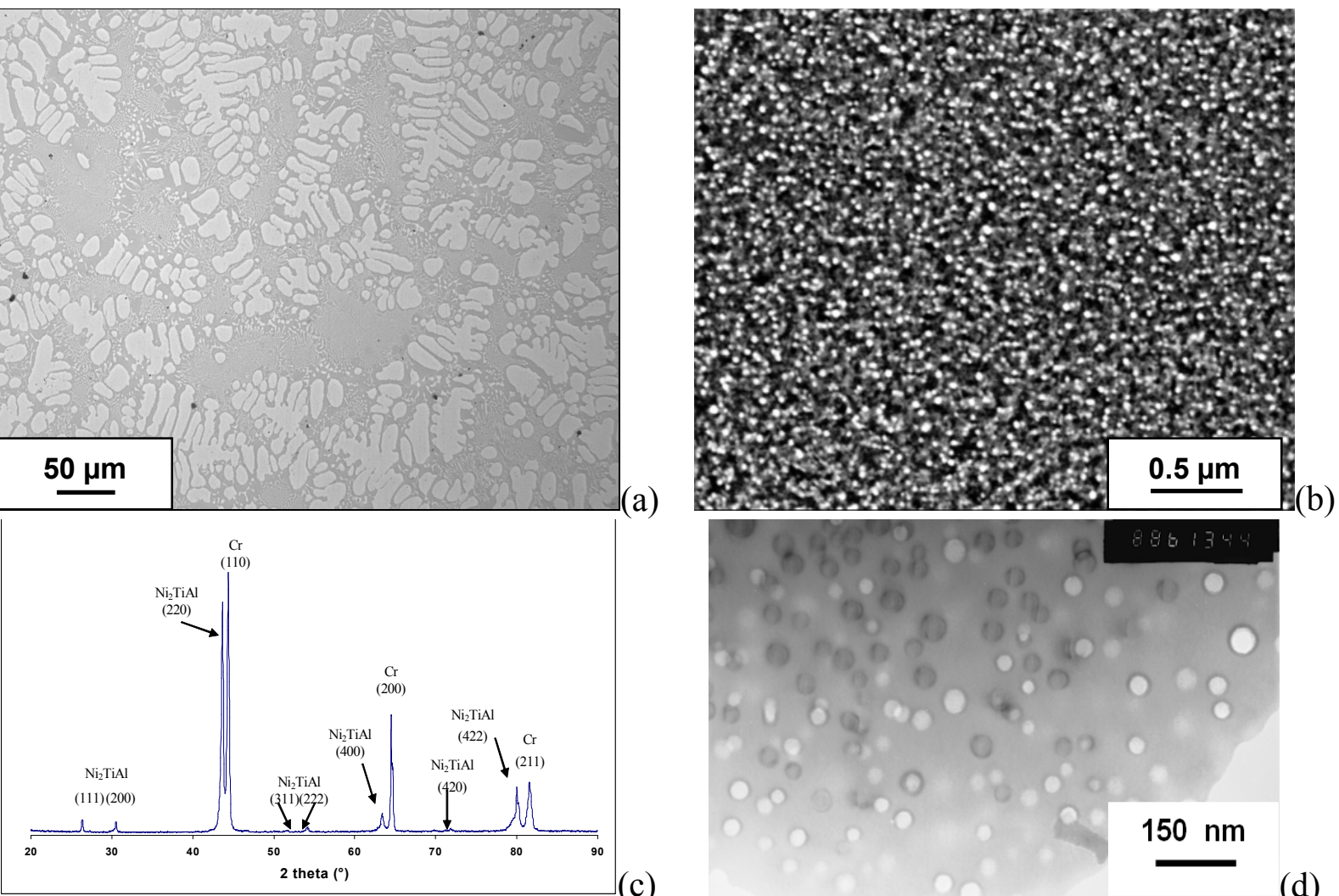

(c)

Fig. 3: RT4 alloy microstructure ((a) OM and (b) SEM) and (c) associated X-ray diffraction diagram.(d) $\mathrm{Ni}_{2}$ AlTi precipitates in the $\alpha$-Cr phase of RT7 alloy (TEM bright field).

Environmental resistance. Cyclic oxidation tests were performed on the five chromium-based alloys at $1100^{\circ} \mathrm{C}$ in laboratory air ( 300 one-hour cycles). The results of these tests are compared in Fig. 4 with those obtained in the same experimental conditions on the AM1 [6] and MC-NG single crystal blade superalloys [7]. The chromium-based alloys experience a continuous mass gain during the 150 first cycles, and then some of these alloys begin to degrade. For the nickel-based superalloys, the mass gain is weaker. As it will be further detailed, the chromium-based alloys have developed chromia scales and the high values of the parabolic rate constant for oxidation $\mathrm{k}_{\mathrm{p}}$ (Eq. 1) confirm this phenomenon.

$$
\left(\frac{\Delta m}{S}\right)^{2}=k_{p} t
$$

where $\mathrm{t}$ is the time, $\Delta \mathrm{m}$ is the mass variation and $\mathrm{S}$ is the sample surface.

For the chromium-based alloys, the $\mathrm{k}_{\mathrm{p}}$ values are in the range $0.5-2.610^{-10} \mathrm{~g}^{2} \cdot \mathrm{cm}^{-4} \cdot \mathrm{s}^{-1}$ at $1100^{\circ} \mathrm{C}$. These values are significantly higher than the expected value for an alumina-former alloy which should not exceed $510^{-12} \mathrm{~g}^{2} \cdot \mathrm{cm}^{-4} \cdot \mathrm{s}^{-1}$ at this temperature [8].

EDS analyses on cross-sections of AM1 and MC-NG samples (for which the oxidation tests were conducted until 1000 cycles) show that the thin $(<5 \mu \mathrm{m})$ oxide scale is $\mathrm{Al}_{2} \mathrm{O}_{3}$ (Fig. 5a). The higher cyclic oxidation resistance of the MC-NG alloy is due to a more dense, flat and adherent layer of $\mathrm{Al}_{2} \mathrm{O}_{3}$ than for $\mathrm{AM} 1$ alloy. This difference could be attributed to the higher hafnium and silicon contents in MC-NG alloy [9]. Some TiN particles were observed beneath the surface in AM1 alloy because of discontinuities in the $\mathrm{Al}_{2} \mathrm{O}_{3}$ scale. 


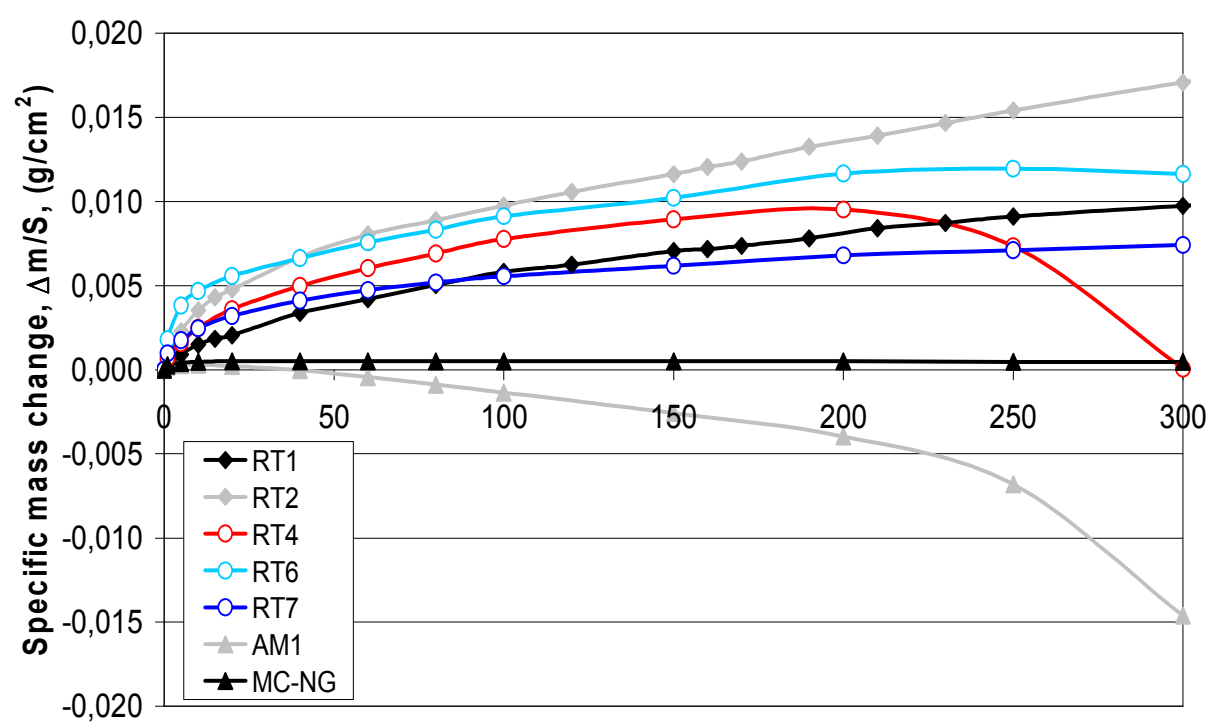

Number of 1-hour cycles

Fig. 4: Cyclic oxidation kinetics of chromium-based alloys and nickel-based superalloys at $1100^{\circ} \mathrm{C}$.

For the chromium-based alloys, no continuous $\mathrm{Al}_{2} \mathrm{O}_{3}$ layer is observed on cross-sections (Fig. $5 b)$. Typically, the alloy area modified by the air exposure includes three distinct zones:

- the outside zone (zone I in Fig. 5b) is made up of chromia with fine alumina particles (30 to $50 \mu \mathrm{m}$ thickness),

- the intermediate zone (zone II) also contains chromia particles and alumina particles (edgings in RT7 alloy) or chromia particles and TiN or AIN particles (in RT4 alloy). In RT7 alloy, TiN particles are present at some $\alpha / \beta$ ' boundaries,

- the internal zone (zone III) where chromia particles are observed in the chromium dendrites.

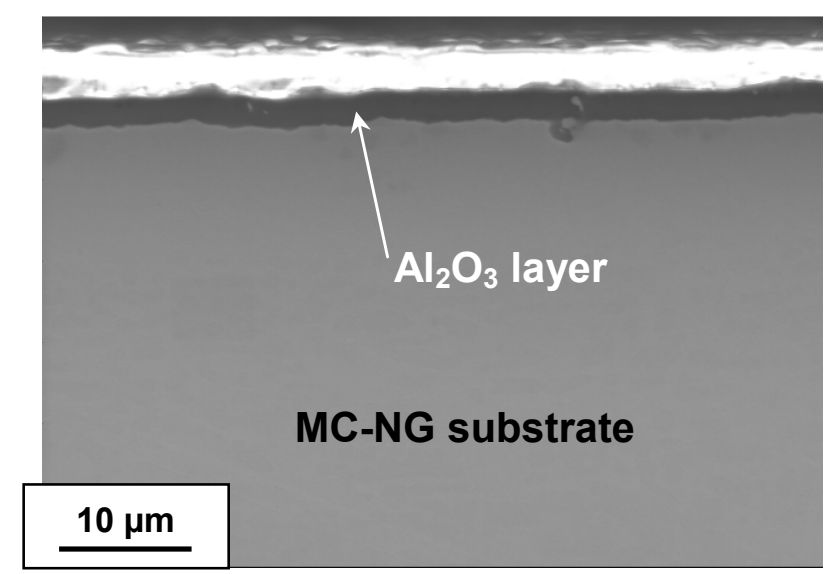

(a)

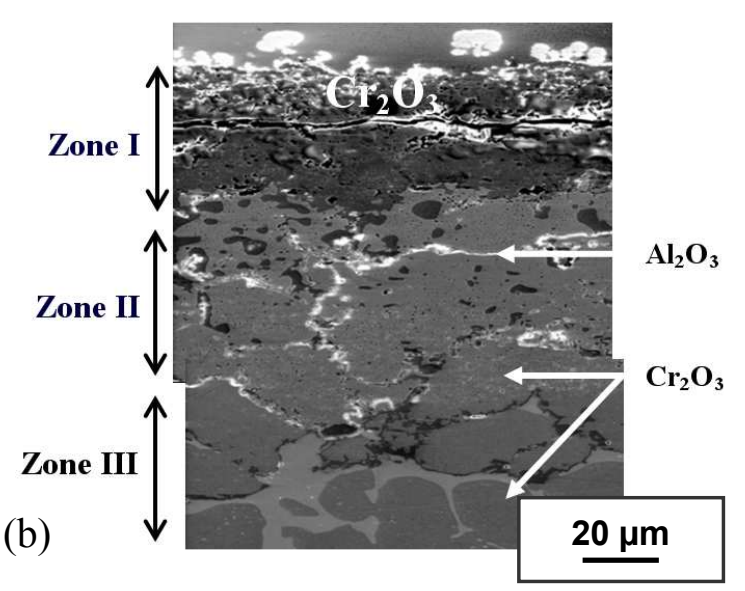

Fig. 5: Cross-section of cyclic oxidation samples (SEM): (a) MC-NG nickel-based superalloy after 1000 one-hour cycles at $1100^{\circ} \mathrm{C}$;(b) RT7 alloy after 300 one-hour cycles at $1100^{\circ} \mathrm{C}$.

The depth of the whole zone affected by the air exposure is about $100 \mu \mathrm{m}$ after 300 cycles at $1100^{\circ} \mathrm{C}$. These observations show that the chromia scale does not prevent further diffusion of oxygen and nitrogen deep into the chromium-based alloys. However a thin, adherent and continuous alumina scale can efficiently protect the substrate against oxidation and nitriding at $1100^{\circ} \mathrm{C}$. It could be also noticed that despite their high aluminium content (12 to 15 at. \%), RT4 and RT2 alloys developed a non-protective chromia scale. 
A complementary study was carried out to promote alumina scale formation on these chromiumbased alloys. Different solutions are briefly described here:

- to design chromium-based alloys (in the same ternary and quaternary systems) with higher aluminium contents (as high as 20 at. \% for ternary alloys and 15 at. \% for the quaternary alloys),

- to carry out an oxidation at $1300^{\circ} \mathrm{C}$ prior to cyclic oxidation at $1100^{\circ} \mathrm{C}$ in order to promote a higher diffusion rate of aluminium,

- to produce a surface layer rich in aluminium by a vapour-phase aluminizing technique.

The materials resulting from these solutions were processed, cyclic oxidation tested (50 one-hour cycles) and observed and analysed in a SEM. Only an aluminizing followed by a pre-oxidation at $1300^{\circ} \mathrm{C}$ ensured the formation of a thin alumina layer which protects the chromium-based samples (Fig. 6).
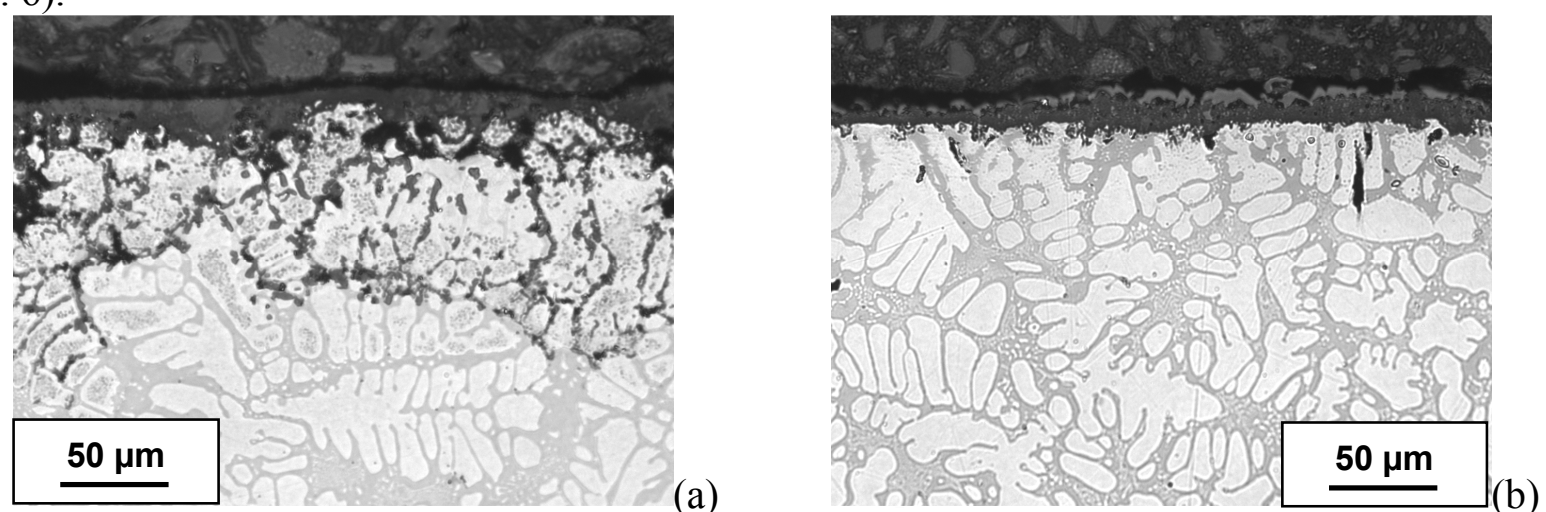

Fig. 6: Cross-sections of cyclic oxidation samples of RT4 alloy (OM image) after 50 cycles of one hour at $1100^{\circ} \mathrm{C}$ : (a) aluminized; (b) aluminized and pre-oxidized $4 \mathrm{~h}$ at $1300^{\circ} \mathrm{C}$.

Mechanical resistance. High-temperature creep tests were carried out on compression specimens of as-cast RT4 and RT7 alloys. The dimensions of the specimens were $3 \times 3 \times 6 \mathrm{~mm}^{3}$. The creep tests were conducted at $1100^{\circ} \mathrm{C}$ by incremental step-loading under dynamic argon to prevent excessive environmental damage. Minimum creep rates were measured after each stress increment and are presented in the Fig. 7. The minimum creep rate of the RT7 alloy is lower than that of RT4. It is supposed that the RT7 alloy which contains more chromium is highly hardened by $\beta^{\prime}$ precipitates in the dendrites. These results were compared to minimum creep rates of polycrystalline pure chromium and other experimental or commercial high-temperature materials. At $1100^{\circ} \mathrm{C}$, it could be noticed that minimum creep rate of RT7 alloy is about 100 times lower than the tensile creep rate of pure chromium [10] at $982^{\circ} \mathrm{C}$. But the comparison with a niobium silicide based alloy crept in vacuum or a commercial single crystal superalloy crept in air shows that RT4 and RT7 alloys present clearly lower creep resistances at $1100^{\circ} \mathrm{C}$ [11].

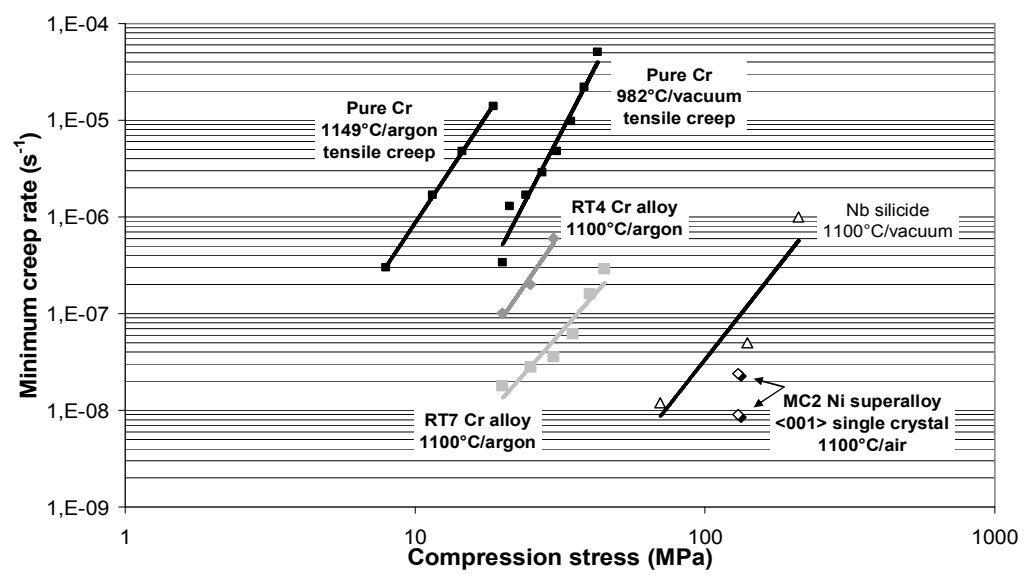

Fig. 7: Compression-creep rate at $1100^{\circ} \mathrm{C}$ of RT4 and RT7 alloys compared with high-temperature materials 


\section{Concluding remarks}

This study shows the possibility to strengthen chromium-based alloys by precipitation of coherent intermetallic compounds $\beta-\mathrm{NiAl}$ or $\beta^{\prime}-\mathrm{Ni}_{2} \mathrm{AlTi}$. Cracks in most of the ingots prove however some brittleness. Oxidation tests indicate that these alloys intrinsically form $\mathrm{Cr}_{2} \mathrm{O}_{3}$ oxide scale despite high aluminium content. Chromia unlike alumina is not protective against oxygen or nitrogen diffusion. Aluminizing followed by a pre-oxidation at $1300^{\circ} \mathrm{C}$ allowed forming a protective alumina layer. The use of powder metallurgy techniques could allow obtaining finer microstructures and so a more homogeneous distribution of aluminium in these alloys.

Despite some promising mechanical testing results and a lower density, these materials could not at present compete with nickel-based superalloys for high-temperature applications. Further heat treatment study has to be undertaken in order to better homogenize and control the precipitation of the strengthening phase in the $\alpha-\mathrm{Cr}$ dendrites. Finally, to complete the study of these alloys, their high ductile-brittle transition temperature should be also assessed.

\section{References}

[1] W.D. Klopp, in: The superalloys, edited by C.T. Sims and W.C. Hagel, John Wiley \& Sons, New-York, USA (1972), p. 175.

[2] W.D. Klopp: J. Less-Common Met., 42 (1975), p. 261.

[3] Y.F. Gu, H. Harada and Y. Ro: JOM, 42 (2004) p. 28.

[4] JCPDS file number 44-1188, JCPDS International Center for Diffraction Data.

[5] JCPDS file number 19-0034, JCPDS International Center for Diffraction Data.

[6] J.H. Davidson, A. Fredholm, T. Khan and J.-M. Théret, French Patent Nº 2557598.

[7] P. Caron, in: Superalloys 2000, edited by T.M. Pollock et al., TMS, Warrendale, PA, USA (2000), p. 737.

[8] H. Hindam, D.P. Wittle: Oxid. Met., 18, 5/6 (1982), p. 245.

[9] P. Caron, S. Navéos and T. Khan: in: Materials for Advanced Power Engineering Part II, edited by D. Coutsouradis et al, Kluwer Academic Publishers, the Netherlands (1994), p. 1185.

[10] J.R. Stephens and W.D. Klopp: Technical Memorandum NASA TM X-2499 (1972).

[11] S. Drawin and P. Caron: private communications (2009). 